\title{
Citogenotoxicidade de águas fluviais urbanas em Presidente Prudente (SP), Brasil, através do teste Allium cepa
}

Vários problemas de saúde podem surgir em decorrência da interação das pessoas com o meio ambiente poluído. Muitos dos contaminantes lançados no meio podem ter propriedades tóxicas e mutagênicas. A detecção desses agentes pode ser realizada através de bioensaios com plantas superiores, como a cebola comum (Allium cepa L.), que é amplamente utilizada devido ao seu baixo custo e sua alta sensibilidade. O objetivo deste trabalho foi avaliar a qualidade da água do córrego do Limoeiro em Presidente Prudente (SP), Brasil, através da análise do potencial citotóxico e mutagênico, por meio do sistema teste Allium cepa em cinco pontos diferentes do córrego e em dois períodos do ano (chuvoso e seco). Através do cálculo e comparação do índice mitótico e anomalias cromossômicas com um controle negativo, observou-se que todos os pontos avaliados apresentaram algum nível de contaminação. Esses dados foram analisados em conjunto com os resultados da análises físico-químicas e biológicas, que também foram realizadas nos mesmo locais. A nascente foi o único local que não apresentou citotoxicidade ou genotoxicidade, mas alguns valores químicos foram relevantes. O Balneário da Amizade (uma área recreativa localizada dentro da área urbana) e o local de lançamento de Estação de Tratamento de Esgoto (ETE) do Limoeiro foram os pontos que foram mais impactados pela poluição, pois apresentaram valores significativos em vários parâmetros analisados e em ambos períodos do ano. Os demais pontos de coleta de amostras apresentaram valores significativos, porém, em menor número de parâmetros ou menor frequência. Outros fatores devem ser avaliados para que tenhamos melhor compreensão dos agentes causadores dessas alterações, sendo que a obtenção de mais dados sobre as fontes poluidoras possibilitará a identificação de outros compostos que possam ter influenciado os resultados obtidos.

\section{Cytogenotoxicity of urban fluvial waters in Presidente Prudente (SP), Brazil, using the Allium cepa test}

\begin{abstract}
Several health problems can arise from the interaction of people with polluted environment. Many of the contaminants thrown in the environment can have toxic and mutagenic properties. Detection of these agents can be performed through bioassays with higher plants, such as common onion (Allium cepa L.), which is widely used, because of its low cost and high sensitivity. This work evaluated the water quality of the Limoeiro stream in Presidente Prudente (SP), Brazil, by analyzing the cytotoxic and mutagenic potential, using the Allium cepa test system in five different points of the stream and in two periods of the year (rainy and dry seasons). By calculating and comparing mitotic index and chromosomal abnormalities with a negative control, we observed that all the evaluated points presented some level of contamination. These data were analyzed together with the results of the physical-chemical and biological analyzes, which were also carried out in the same places. The springs were the only place that did not present cytotoxicity or genotoxicity, but some chemical values were relevant. The Balneário da Amizade (a recreational area located within the urban area) and the effluent place of Limoeiro Sewage Treatment Station (STS) were the points that were most impacted by pollution, since they presented significant values in several analyzed parameters and in both periods of the year. The other sample collection points showed significant values, however, in a smaller number of parameters or less frequently. Other factors should be evaluated in order to have a better understanding of the agents that cause these changes, and obtaining more data on the polluting sources will enable the identification of other compounds that may have influenced the results obtained in this work.
\end{abstract}

Keywords: Allium cepa test; Citogenotoxicity; Environmental biomonitoring.

Topic: Desenvolvimento, Sustentabilidade e Meio Ambiente

Reviewed anonymously in the process of blind peer.

Ana Carolina Preto Malaman (iD)

Universidade do Oeste Paulista, Brasil

http://lattes.cnpq.br/5640599499957744

http://orcid.org/0000-0002-5889-5228

carolmalaman@hotmail.com

Antonio Fluminhan Junior

Universidade Estadual Paulista Júlio de Mesquita Filho, Brasil

http://lattes.cnpq.br/0281983303003998

http://orcid.org/0000-0002-2571-0792

fluminhan@hotmail.com

\section{Wellynton de Lima Silva (iD}

Universidade do Oeste Paulista, Brasil

http://lattes.cnpq.br/5609490600024917

http://orcid.org/0000-0003-3946-7065

welly123silva@gmail.com

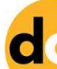

DOI: 10.6008/CBPC2179-6858.2020.002.0026
Received: 06/02/2020

Approved: 04/03/2020 lago Fernandes Santos (iD)

Universidade do Oeste Paulista, Brasil http://lattes.cnpq.br/0327113745378731 http://orcid.org/0000-0003-0397-9544 iagro@outlook.com.br

Paulo Antonio da Silva (iD)

Universidade do Oeste Paulista, Brasil http://lattes.cnpq.br/6213603526706261 http://orcid.org/0000-0002-6813-1061 pauloantonio@unoeste.br

\section{Referencing this:}

MALAMAN, A. C. P.; FLUMINHAN JUNIOR, A.; SILVA, W. L.; SANTOS, I. F.; SILVA, P. A.. Citogenotoxicidade de águas fluviais urbanas em Presidente Prudente (SP), Brasil, através do teste Allium cepa. Revista Ibero Americana de Ciências Ambientais, v.11, n.2, p.249-265, 2020. DOI: $\underline{\text { http://doi.org/10.6008/CBPC2179-6858.2020.002.0026 }}$ 


\section{INTRODUÇÃO}

Atualmente muitos problemas de saúde em seres humanos são atribuídos à contaminação do meio ambiente por resíduos decorrentes das atividades humanas (VANZELLA et al., 2007). Alguns tipos de câncer podem estar associados à utilização de água contaminada por resíduos industriais que são lançados propositalmente nos cursos d'água, ou por resíduos urbanos e agrícolas que são carregados de forma difusa através do escoamento pluvial (VILLANUEVA et al., 2007; RICHARDSON et al., 2007). A liberação de poluentes em corpos hídricos de forma inadequada é, muitas vezes, clandestina, principalmente em grandes centros urbanos cuja gestão ambiental dos resíduos e efluentes não acompanhada de forma adequada o crescimento econômico e populacional (BOAVENTURA et al., 2010).

O monitoramento da qualidade das águas superficiais, e a realização dos bioensaios, são importantes ferramentas no estudo de impactos ambientais devido à complexidade e a relação entre os compostos poluidores, que muitas vezes não conseguem ser estimados através das avaliações físico-químicas apenas (PEREIRA et al., 2017). Ambos devem ser aplicados, simultaneamente, como forma de avaliar a qualidade do corpo d'água e saúde dos ecossistemas ao qual os mesmos estão envolvidos (FISKESJÖ, 1985). Para a avaliação, detecção de contaminantes e biomonitoramento em ambientes de importância regional os bioensaios com plantas superiores têm sido amplamente utilizados, sendo o teste Allium cepa L. um dos mais indicados, em conjuntos com as demais técnicas de monitoramento ambiental existentes (EVSEEVA et al., 2003). O teste de Allium cepa L. é considerado uma ferramenta útil para a pesquisa básica do potencial genotóxico e citotóxico de produtos químicos, substâncias complexas como extratos de plantas, dejetos industriais, radiação eletromagnética e águas contaminadas (FISKESJÖ, 1985; GRANT, 1994; CHANDEL et al., 2019). Esse método tem sido recomendado para análises de efluentes contaminados e validado internacionalmente como bioindicador de amostras ambientais devido à sua elevada sensibilidade, baixo custo, rapidez e facilidade de manipulação, utilizando-se o índice mitótico e a formação de anomalias cromossômicas como parâmetros de avaliação da poluição ambiental (RANK et al., 1994; BONCIU et al., 2018).

A partir de dados observados em um grande número de estudos, pode-se concluir que o potencial citotóxico e mutagênico de corpos d'água depende do contexto ao qual ele está inserido. Locais com grande atividade industrial demonstram potencial mutagênico mais elevado em relação a locais com outros tipos de atividades econômicas, tais como: a agropecuária, lavouras ou mesmo as regiões urbanas (ANACLETO et al., 2017; HARA et al., 2017; BOLLANI et al., 2018; OGUNYEMI et al., 2018). O regime de chuvas e fatores climáticos também são variáveis que devem ser consideradas, pois estudos feitos em períodos de seca demonstraram maiores potenciais citotóxicos se comparados aos períodos de chuva, onde há maior diluição das amostras da água coletada (CUCHIARA et al., 2012).

O presente trabalho objetivou avaliar a qualidade das águas de um córrego urbano através do seu potencial citotóxico e mutagênico, e assim estimar o impacto ambiental causado pelas atividades antropogênicas da região de Presidente Prudente/SP, considerada uma cidade de médio porte com grande 
desenvolvimento urbano industrial. Foram realizados bioensaios com o objetivo de avaliar a citotoxicidade e a genotoxicidade das águas coletadas no córrego do Limoeiro, por meio do sistema teste Allium cepa como bioindicador. Além disso foi possível investigar a interferência de diferentes atividades humanas na qualidade da água do córrego, determinando 5 pontos amostrais inseridos em diferentes contextos locais ao longo do curso do córrego.

Outros objetivos do trabalho incluíram a avaliação da sazonalidade das observações, através da análise em dois períodos do ano, sendo um caracterizado pela predominância de precipitação (verão) e o outro pelos baixos índices de chuva e umidade (inverno), bem como a realização de análises físico-químicas e biológicas da água coletada nos diferentes pontos de amostragem, em conjunto com as análises de citogenotoxicidade e genotoxicidade. Esse trabalho visa contribuir com informações sobre os potenciais efeitos da poluição ambiental sobre o córrego urbano avaliado, além de fornecer subsídios que possam servir de alerta para possíveis ações de preservação.

\section{MATERIAIS E MÉTODOS}

\section{Características da área de estudo}

Presidente Prudente é considerada uma cidade de médio porte, sendo que a sua população registrada no censo de 2010 foi de 207.610 habitantes e a projeção para 2018 foi de 227.072 habitantes (IBGE, 2019). A sua localização geográfica compreende o paralelo $22^{\circ} 07^{\prime} 57^{\prime \prime}$ S e o meridiano $51^{\circ} 22^{\prime} 57^{\prime \prime} \mathrm{W}$, sendo o seu clima do tipo tropical continental sub-úmido e caracterizado por um verão quente e chuvoso e um inverno frio e seco (AMORIM et al., 2009). Neste município existe um sistema hidrográfico constituído por pequenos cursos d'água, como o córrego do Botafogo e do Veado, respectivamente, formadores dos córregos do Cedro e do Limoeiro. Ambos são afluentes do rio Santo Anastácio, um importante rio do Oeste do Estado de São Paulo, Brasil, e que já foi o principal rio responsável pelo abastecimento público de água da cidade de Presidente Prudente (SP), Brasil, (TEODORO et al., 2011).

De acordo com Honda et al. (2015), a expansão territorial e a ocupação do solo urbano em Presidente Prudente - SP não se estabeleceu de forma planejada, assim, muitos cursos d'água formadores desta bacia hidrográfica atravessam área com grande desenvolvimento urbano industrial. O córrego do Limoeiro é um corpo hídrico superficial que se encontra inserido na Unidade de Gerenciamento de Recursos Hídricos do Pontal do Paranapanema (UGRHI22) e que constitui, em parte, o limite geográfico dos municípios de Presidente Prudente e Álvares Machado e que também é receptor de efluentes da Estação de Tratamento de Esgoto (ETE) de ambos municípios (TAKENAKA et al., 2013). Ele também constitui o Balneário da Amizade, uma área recreacional urbana que, ultimamente, sofre um intenso processo de urbanização com alto índice de atividade antropogênica (BOAVENTURA et al., 2010). De acordo com a resolução CONAMA no. 357/2005 (BRASIL, 2005) ele se enquadra na classe 4, o qual deve ser destinado à navegação, harmonia paisagística e a usos menos exigentes. Entretanto, apesar desta recomendação, verifica-se que o córrego é utilizado na irrigação de pomares e lavouras, dessedentação de animais, pesca amadora e recreação, atividades 
atribuídas à classe 3 da mesma resolução.

Apesar do córrego do Limoeiro ser muito utilizado nas atividade humanas, muitos efluentes são lançados ao longo do seu percurso, seja em área urbana ou no caso da Estação de Tratamento de Esgotos ETE Limoeiro, construída pela SABESP (Companhia de Saneamento Básico do Estado de São Paulo) em 1997, que despeja esgoto tratado com diversas substâncias químicas, além das águas pluviais oriundas do córrego do Veado, e de diversos bairros localizados às margens do Balneário da Amizade, nos levando a supor que haja presença de substâncias poluidoras potencialmente citotóxicas e mutagênicas em seu percurso.

As amostras foram coletadas na superfície do córrego utilizando recipientes de vidro âmbar e mantidas em caixa térmica com gelo durante o período amostral e até serem transportadas para o laboratório, onde ficaram armazenadas no refrigerador a $4^{\circ} \mathrm{C}$ até aplicação dos métodos de análises, de acordo com as recomendações do Guia Nacional de coleta e Preservação de Amostras (CETESB, 2011).

As coletas foram realizadas em dois períodos do ano, a fim de avaliar as influências das diferentes condições climáticas de cada período. A primeira coleta aconteceu no verão, período caracterizado pelas altas médias de precipitação e a segunda coleta no inverno, período caracterizado pelas baixas médias pluviométricas. As datas das coletas das amostras de água também foram determinadas de acordo com o Guia Nacional de Coleta e Preservação de Amostras (CETESB, 2011), que sugere um período de 24 horas sem ocorrência de chuvas precedendo a coleta, para que não ocorra alterações dos resultados. Seguindo essa orientação, as coletas foram realizadas nos dias 26 de fevereiro de 2018 (período chuvoso), e 10 de setembro de 2018 (período seco).

O mapa de satélite mostrando os pontos selecionados para as coletas de amostras estão indicados na Figura 1, onde estão assinalados os pontos (P1, P2, P3, P4 e P5) que representam cinco condições ambientais diferentes com contexto de atividades humanas distintas. P1 está localizado próximo à nascente do córrego e foi escolhido por representar uma área preservada pela legislação, presumindo-se que sofra pouca interferência antrópica. P2 localiza-se à margem do Balneário da Amizade, local onde foi realizado o represamento do córrego no final da década de 1970 através de uma iniciativa conjunta dos municípios de Presidente Prudente (SP) e Álvares Machado (SP) com fins recreativos e, posteriormente, para o abastecimento urbano (SOARES et al., 2011).

O Córrego do Veado, que está representado por uma linha na cor cinza na Figura 1, possui sua nascente dentro da área urbana de Presidente Prudente e percorre toda a cidade, carregando significativa parcela do escoamento pluvial e efluentes de várias indústrias da região (TAKENAKA et al., 2013). Por este motivo P3, foi posicionado à $1,5 \mathrm{Km}$ à jusante da foz do córrego do Veado no córrego do Limoeiro, para que pudéssemos identificar contaminação proveniente da área urbana. P4 está localizado imediatamente após o local de despejo do esgoto tratado pela Estação de Tratamento de Esgoto do Limoeiro - ETE/SABESP, que atende aos municípios de Presidente Prudente (SP) e Álvares Machado (SP). P5 está localizado a cerca de seis quilômetros de distância do despejo do esgoto tratado pela ETE do Limoeiro, antes de sua confluência com o rio Santo Anastácio. Durante esse percurso, que está distante cerca de oito quilômetros da região urbana, ocorre a autodepuração do córrego. 


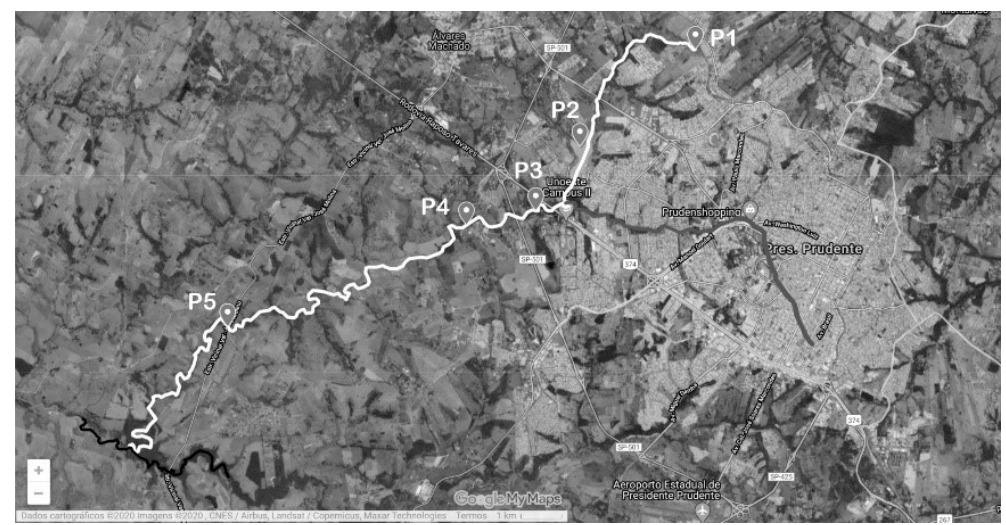

Figura 1: Mapa da região de Presidente Prudente - SP, onde está situado o córrego do Limoeiro (representado pela linha branca), apresentando os cinco pontos de coleta. P1; P2; P3; P4 e P5. A linha na cor cinza representa o curso do Córrego do Veado e a linha na cor preta representa o curso do Rio Santo Anastácio. Fonte: Google Maps (2019).

Após a coleta, as amostras de água foram encaminhadas para o laboratório de análises químicas da Universidade do Oeste Paulista, onde ficaram armazenadas sob refrigeração de $4^{\circ} \mathrm{C}$ até o preparo para as análises. Os métodos de preservação de amostras estão preconizados no Standard Methods for Examination of Water and WasteWater, 21a Edition (APHA, 2012).

Foram determinados os parâmetros para DBO (demanda bioquímica de oxigênio) (mg.L-1 $)$ através do método respirométrico simplificado; DQO (demanda química de oxigênio) (mg. $\mathrm{L}^{-1}$ ) através do método colorimétrico; e a análise microbiológica de coliformes fecais (NMP/100mL) e coliformes totais (NMP/100mL) através da técnica da membrana filtrante em meio ágar seletivo.

Para o preparo e análise de metais pesados, as amostras de água foram submetidas à digestão por via ácida e, posteriormente, filtradas e transferidas para recipiente de vidro âmbar, conservadas sob refrigeração até a leitura. As leituras das concentrações dos metais pesados foram realizadas através do Espectrômetro de Absorção Atômica de Chama (FAAS), marca Perkin Elmer - Modelo A Analyst 200 equipado com lâmpada de deutério como corretor de fundo e lâmpadas de cátodo-oco contendo analito. Para atomização dos metais usou-se o gás acetileno.

Para as análises biológicas foram utilizados seis bulbos de Allium cepa L. (cebola comum) para cada grupo tratamento e para os controles, onde P1, P2, P3, P4, P5 representavam os cinco pontos de coleta, CN o controle negativo (água mineral) e CP o controle positivo (contendo solução de peróxido de hidrogênio $\left(\mathrm{H}_{2} \mathrm{O}_{2}\right)$ a $0,3 \mathrm{M}$ ). No total, foram utilizados 42 (quarenta e dois) bulbos para os testes realizados no período chuvoso e a mesma quantidade de bulbos para os testes realizados no período de estiagem. O número de amostras sugeridas por Barbério et al. (2011) é de no mínimo três bulbos para que se tenha resultados estatísticos significativos. Todos os bulbos foram adquiridos no mesmo estabelecimento comercial e de uma mesma remessa proveniente de uma única lavoura. Foram escolhidos bulbos jovens, com características morfológicas similares entre si, com diâmetro aproximado de $40 \mathrm{~mm}$, simétricos e sem sinais de danos, doenças ou malformações.

O teste com as células meristemáticas de Allium cepa L. foi realizado com base no protocolo desenvolvido e estabilizado por Grant (1982) e adaptado de acordo com Vicentini et al. (2001) e Camparoto et al. (2002) com algumas modificações. Os bulbos foram acondicionados em recipientes de vidro 
preenchidos com os controles e os tratamentos, de forma que apenas a região radicular da cebola ficasse submersa. Os recipientes com os bulbos foram dispostos em ambiente com luz natural indireta. Os bulbos ficaram em contato com água mineral por 72 horas para estimular o início do crescimento de raízes e identificar a viabilidade dos bulbos. As raízes foram removidas logo após o término desse período. Realizouse então, a substituição da água dos recipientes pela água coletada do Córrego do Limoeiro e dos controles em cada grupo. Ao final de mais $72 \mathrm{~h}$, as novas raízes (que cresceram a partir dos bulbos sob o tratamento) foram coletadas. O período de 72 horas é baseado no ciclo de divisão celular das células da cebola que é de aproximadamente 24 horas, segundo González-Fernandes et al. (1966). Desta forma, pode-se observar no mínimo três ciclos celulares e avaliar a presença de eventuais anomalias mitóticas e cromossômicas que ficam evidentes nas células filhas.

Para as análises citogenéticas, as raízes com comprimento inferior a 20 milímetros foram retiradas com o auxílio de pinça e fixadas por um período de 24h sob temperatura ambiente em solução Carnoy (3:1, álcool etílico absoluto: ácido acético glacial) em frascos devidamente etiquetados e identificados. Posteriormente foram transferidas para recipientes contendo solução de etanol a $70 \%$ e conservadas sob refrigeração a $4^{\circ} \mathrm{C}$ até o preparo das lâminas.

Para o pré-preparo das lâminas, as raízes foram hidrolisadas em solução de ácido clorídrico $(\mathrm{HCl})$ a $1 \mathrm{~N}$ por 10 minutos em banho maria a $60^{\circ} \mathrm{C}$ e lavadas com água destilada. Em seguida, as regiões meristemáticas das raízes foram coradas com reativo de Schiff, através da técnica de coloração de Feulgen, e intensificadas com solução de Carmim acético a 2\% (MELLO et al., 2017).

As lâminas foram preparadas através da técnica de esmagamento (GUERRA et al., 2002) e fotografadas em microscópio ótico de campo claro, modelo Leica ICC50 HD, sob objetiva de 40x, através da técnica de varredura. Foram contadas aproximadamente 6000 (seis mil) células por ponto de coleta de amostras (total de 1000 células por bulbo), observando-se e anotando o número de células em cada fase da mitose. Desta forma, o índice mitótico (IM) pôde ser estabelecido através da divisão das células em mitose pelo número de células totais contadas como descrito na fórmula: $\quad I M=\left(\frac{n-\text { total de células em divisão }}{n+\text { total de células analisadas }}\right) \times 100$

A frequência de anomalias cromossômicas ( $A C$ ) observáveis também foi determinada através da contagem do número de células normais em divisão e do número de células que apresentavam anomalias durante a mitose. Foram consideradas anomalias as pontes cromossômicas durante a anáfase e a telófase, o atraso na separação de cromátides irmãs, a ocorrência de cromossomos pegajosos, fragmentos cromossômicos, C-mitoses e poliploidia, entre outras anomalias.

A fórmula utilizada para cálculo do AC foi:

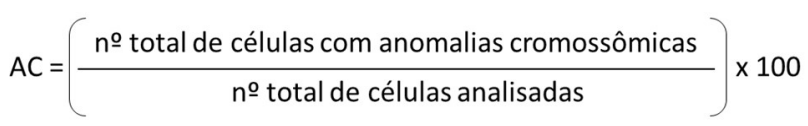

Os dados foram anotados em planilhas individuais para cada um dos grupos de controle e tratamentos. As análises estatísticas foram conduzidas usando o programa Graphpad Prism $7.0^{\circ}$. Os valores contabilizados foram tratados, excluindo os dados faltantes e substituindo os quocientes, cujo divisor era igual a zero pela média total do grupo. Os dados foram então submetidos à análise de variância (ANOVA) 
seguidos do teste de Dunnett, para a comparação dos grupos tratamento com o grupo controle, e teste de

Tukey, para a comparação dos grupos entre si e ao nível de 5\% de probabilidade.

\section{RESULTADOS E DISCUSSÃO}

\section{Períodos das coletas}

Os dados referentes aos índices de precipitação dos meses das análises estão descritos na Tabela 1 e na Tabela 2. Através destes dados, observou-se que os períodos de coleta retrataram as condições climáticas esperadas para avaliação da influência da sazonalidade. Os valores acumulados nos 30 dias anteriores à coleta do período chuvoso foram de $229,7 \mathrm{~mm}$ de chuva. $\mathrm{O}$ valor acumulado nos 30 dias anteriores à coleta do período seco foi consideravelmente menor, com $40,2 \mathrm{~mm}$ de precipitação. Isso corresponde à pouco mais de $17 \%$ do valor total referente ao período chuvoso.

Tabela 1: Dados pluviométrico registrados durante o período chuvoso de 2018.

\begin{tabular}{|l|l|l|}
\hline Período Chuvoso & Data & Precipitação $(\mathrm{mm})$ \\
\hline Data da coleta & $26 / 02 / 2018$ & 0 \\
\hline 10 dia anteriores & $16 / 02$ a $26 / 02$ & 92,9 \\
\hline 30 dias anteriores & $26 / 01$ à $26 / 02$ & 229,7 \\
\hline
\end{tabular}

Fonte: Somar Meteorologia (2019).

Tabela 2: Dados pluviométrico registrados durante o período seco de 2018.

\begin{tabular}{|l|l|l|}
\hline Período Seco & Data & Precipitação $(\mathrm{mm})$ \\
\hline Data da coleta & $10 / 09 / 2018$ & 0 \\
\hline 10 dia anteriores & $01 / 09$ à $10 / 09$ & 1,1 \\
\hline 30 dias anteriores & $10 / 08$ à $10 / 09$ & 40,2 \\
\hline
\end{tabular}

Fonte: Somar Meteorologia (2019)

\section{Análises físico-químicas e microbiológicas}

Os valores obtidos nas análises físico-químicas e microbiológicas de ambos períodos estão demonstrados na Tabela 3 e na Tabela 4. Apesar do córrego do Limoeiro ser classificado como Classe 4 de acordo com a resolução CONAMA no. 357/2005 (BRASIL, 2005), esse enquadramento não reflete a real atividade realizada no local, pois durante o trabalho de campo pode-se constatar que o rio é utilizado para dessedentação de animais nas áreas rurais, irrigação de pomares, atividades recreativas, lazer e pesca. Portanto, os valores de referência que utilizamos como parâmetros máximos foram correspondentes à Classe 3, que abrange todas as atividades supracitadas.

\section{Período Chuvoso}

A Tabela 3 mostra que, no período chuvoso, os pontos que apresentaram menor quantidade de bactérias E. coli foram os pontos de coleta P1 (nascente) e P4 (próximo à recepção dos efluentes da ETE). Foi observado que o ponto de coleta P3, referente à proximidade da descarga do córrego do Veado, foi o único local onde os valores observados ficaram acima dos valores de referência do CONAMA que é de 1000 $\mathrm{NMP} / 100 \mathrm{~mL}$. 
Em relação às análises químicas, os pontos de coleta P2 (Balneário da Amizade) e P4 (ETE) tiveram valores de DBO (demanda bioquímica de oxigênio) superior ao limite estabelecido pelo CONAMA, sendo que P2 apresentou valor muito superior ao parâmetro máximo preconizado (Tabela 3). O valor DBO é utilizado para estimar a carga orgânica dos recursos hídricos, e valores muito altos indicam que a matéria orgânica presente utiliza grande parte o oxigênio dissolvido disponível para sua oxidação no processo de degradação (CONAMA, 2005).

As concentrações de cobre, cádmio e cromo apresentaram valores superiores aos limites determinados pelo CONAMA em todos os pontos, enquanto o zinco ficou abaixo em todos os pontos, mesmo com P3 apresentando valor bem maior que os demais. Os valores de chumbo, apesar de superiores ao recomendado em apenas dois pontos (P2 e P5), ficaram muito próximos do limite máximo nos demais pontos.

Tabela 3: Análises físico-químicas e microbiológicas referentes ao mês de fevereiro de 2018 (período chuvoso).

\begin{tabular}{|c|c|c|c|c|c|c|c|c|c|}
\hline Ponto & $\begin{array}{l}\text { Escherichia coli } \\
\text { (NMP/100ml) }\end{array}$ & $\begin{array}{l}\text { Coliformes Totais } \\
(\mathrm{NMP} / 100 \mathrm{ml})\end{array}$ & $\begin{array}{l}\text { DBO } \\
(\mathrm{mg} / \mathrm{L})\end{array}$ & $\begin{array}{l}\mathrm{DQO} \\
(\mathrm{mg} / \mathrm{L})\end{array}$ & $\begin{array}{l}\mathrm{Cu} \\
(\mathrm{mg} / \mathrm{L} \\
1\end{array}$ & $\begin{array}{l}\mathrm{Zn} \\
(\mathrm{mg} / \mathrm{L} \\
1\end{array}$ & $\begin{array}{l}\text { Cd } \\
(\mathrm{mg} / \mathrm{L} \\
1\end{array}$ & $\begin{array}{l}\mathrm{Pb} \\
(\mathrm{mg} / \mathrm{L} \\
1\end{array}$ & $\begin{array}{l}\mathrm{Cr} \\
(\mathrm{mg} / \mathrm{L} \\
)\end{array}$ \\
\hline P1 & 5 & 220 & 0,05 & 16,22 & 0,29 & 0,07 & 0,14 & 0,03 & 0,09 \\
\hline $\mathrm{P} 2$ & 230 & 1340 & 55,24 & 78,92 & 0,19 & 0,36 & 0,09 & 0,04 & 0,11 \\
\hline P3 & 1500 & 5500 & 6,65 & 35,11 & 0,24 & 1,76 & 0,11 & 0,02 & 0,13 \\
\hline P4 & 0 & 4500 & 11,65 & 44,00 & 0,15 & 0,43 & 0,15 & 0,03 & 0,22 \\
\hline P5 & 230 & 880 & 3,65 & 10,67 & 0,28 & 0,32 & 0,11 & 0,06 & 0,14 \\
\hline $\begin{array}{l}\text { Parâmetros } \\
\text { máximos** }\end{array}$ & 1000 & - & 10 & - & 0,013 & 5 & 0,01 & 0,033 & 0,05 \\
\hline
\end{tabular}

Fonte: Malaman (2019).

Nota: *De acordo com a resolução do CONAMA № 357/2005 para Classe 3/ Águas Doces

$\mathrm{Cu}=$ cobre; $\mathrm{Zn}=$ zinco; $\mathrm{Cd}$ = cádmio; $\mathrm{Pb}=$ chumbo; $\mathrm{Cr}=$ Cromo

A partir dessas informações pode-se constatar que todos os pontos apresentaram algum grau de contaminação no período chuvoso, destacando P1 com altos níveis de cobre e cádmio, P2 com grande presença de matéria orgânica, P3 com os maiores valores de coliformes fecais e zinco, P4 com maior concentração de cádmio e cromo, e P5 com valores de cobre e chumbo mais elevados.

\section{Período Seco}

Os dados obtidos no período seco estão apresentados na Tabela 4, onde se pode constatar que as análises biológicas para detecção de E. coli demostraram que as amostras coletadas em P1, P2 e P3 apresentaram valores inferiores no período seco em relação ao período chuvoso. Os valores observados nos pontos P4 e P5 foram superiores no período seco em comparação ao período chuvoso. Entretanto, foi constatado que somente a amostra coletada em P5 apresentou valor maior que o determinado pelo CONAMA, enquanto os outros pontos apresentaram valores abaixo desse limite.

Para a análise de DBO, o único ponto que extrapolou o limite legal foi P4, sendo constatado um valor superior aos valores do mesmo ponto no período chuvoso. Nas análises de metais, as concentrações de cobre foram superiores ao limite legal em todos os pontos, porém menores que as concentrações do período chuvoso em 4 pontos. Apenas P4 apresentou uma concentração deste metal superior ao que foi observada no período chuvoso. As concentrações de zinco apresentaram valores menores se comparados aos valores 
observados no período chuvoso e muito inferiores aos determinados pelo CONAMA. A concentração de cromo foi superior ao limite legal em quatro dos cinco pontos avaliados, sendo que somente P1 não apresentou traços detectáveis deste elemento. Além disso, foram observadas concentrações maiores de cromo no período seco nos pontos P3, P4 e P5, em relação ao período chuvoso. No caso do cádmio e chumbo, as quantidades presentes nas amostras não foram detectáveis pelo equipamento. Devido a improbabilidade da ausência desses metais nas amostras e tendo como base as análises realizadas no período anterior, podese considerar que as concentrações eram menores que as concentrações detectáveis pelo equipamento. Portanto esses dados não foram considerados nas análises realizadas posteriormente.

Tabela 4: Análises físico-químicas e microbiológicas referentes ao mês de setembro de 2018 (período seco).

\begin{tabular}{|c|c|c|c|c|c|c|c|c|c|}
\hline Ponto & $\begin{array}{l}\text { Escherichia coli } \\
\text { (NMP/100ml) }\end{array}$ & $\begin{array}{l}\text { Coliformes totais } \\
(\mathrm{NMP} / 100 \mathrm{ml})\end{array}$ & $\begin{array}{l}\text { DBO } \\
(\mathrm{mg} / \mathrm{L})\end{array}$ & $\begin{array}{l}\text { DQO } \\
\text { (mg/L) }\end{array}$ & $\begin{array}{l}\mathrm{Cu} \\
(\mathrm{mg} / \mathrm{L} \\
)\end{array}$ & 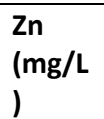 & $\begin{array}{l}\text { Cd } \\
(\mathrm{mg} / \mathrm{L} \\
)^{2}\end{array}$ & $\begin{array}{l}\mathrm{Pb} \\
(\mathrm{mg} / \mathrm{L} \\
)\end{array}$ & $\begin{array}{l}\mathrm{Cr} \\
(\mathrm{mg} / \mathrm{L} \\
)\end{array}$ \\
\hline P1 & 0 & 165 & 0,65 & 10,67 & 0,19 & 0,12 & $0^{*}$ & $0^{*}$ & 0 \\
\hline P2 & 20 & 140 & 3,65 & 17,33 & 0,16 & 0,16 & 0* & 0* & 0,11 \\
\hline P3 & 135 & 1450 & 7,21 & 97,33 & 0,23 & 0,16 & 0* & 0* & 0,26 \\
\hline P4 & 340 & 1200 & 27,21 & 90,67 & 0,24 & 0,17 & 0* & 0* & 0,44 \\
\hline P5 & 1500 & 5500 & 5,65 & 54 & 0,26 & 0,12 & 0* & 0* & 0,27 \\
\hline $\begin{array}{l}\text { Parâmetros } \\
\text { máximos** }\end{array}$ & 1000 & & 10 & & 0,013 & 5 & 0,01 & 0,033 & 0,05 \\
\hline
\end{tabular}

Fonte: Malaman (2019).

Nota: *Devido a improbabilidade da ausência desses metais nas amostras e tendo como base análises do período anterior, consideramos possível falha do equipamento durante a leitura ou pouca sensibilidade de detecção dos traços desses metais. Portanto não validamos esses dados.

**De acordo com a resolução do CONAMA № 357/2005 para Classe 3/ Águas Doces

$\mathrm{Cu}=$ cobre; $\mathrm{Zn}=$ zinco; $\mathrm{Cd}=$ cádmio; $\mathrm{Pb}=$ chumbo; $\mathrm{Cr}=$ Cromo.

Em síntese, no período seco foi verificado que todos os pontos apresentaram algum grau de contaminação. Foi constatado que P1 apresentou um nível de cobre superior ao limite, P2 e P3 com cobre e cromo acima dos limites, P4 apresentou DBO, cobre e cromo em valores acima do permitido e P5 com altos níveis de coliformes fecais, cobre e cromo, sendo que todos estes parâmetros extrapolam os valores determinados pela resolução do CONAMA (2005).

Sabe-se que a maioria dos metais pesados são encontrados naturalmente no ambiente natural em pequenas concentrações, porém em altas concentrações podem causar danos ao ecossistema, devido à bioacumulação, podendo causar mutação no material genético dos organismos vivos (FLOREA et al., 2006). O chumbo é o único metal que parece ter apenas efeitos tóxicos e nenhuma função essencial ao organismo dos seres vivos. Ele está presente principalmente no revestimento de motores, em baterias elétricas, em alguns pigmentos, tintas e, principalmente, nos produtos industrializados e na gasolina como um aditivo, sendo as atividades relacionadas a esses produtos as principais fontes de contaminação ambiental (GERBER et al., 1980). Em concentrações intermediárias, esse elemento químico tem capacidade de inibir o crescimento celular em raízes de Allium cepa e, em concentrações acima de 50ppm, provocam o bloqueio da divisão celular (LERDA, 1992).

O cádmio é carcinogênico e atua como um agente mutagênico muito potente, devido à sua meiavida extremamente longa. Essa propriedade faz com que se acumule com facilidade no meio ambiente. Naturalmente, ele é produzido pela atividade vulcânica e transportado pelos ventos, mas suas principais 
fontes de contaminação estão relacionadas à produção de produtos plásticos do tipo PVC (onde atua como estabilizante), além de também ser encontrado em pigmentos, baterias recarregáveis e até mesmo o cigarro (FILIPIČ, 2012). O cromo é um elemento essencial à atividade metabólica da glicose nos animais. Sua forma hexavalente é facilmente absorvida pela membrana celular e reduzida para a forma trivalente. Entretanto, o cromo hexavalente é a única forma do metal que geralmente causa efeitos tóxicos à indivíduos expostos (MATSUMOTO et al., 2004). Segundo os autores, processos industriais como a curtição de couro através da utilização do processo Wet-blue e a produção de aço inoxidável são as principais fontes de poluição deste elemento.

O cobre também é um metal essencial, porém, em altos níveis, pode ser perigoso devido à formação de espécies reativas de oxigênio (PRÁ et al., 2008). Este elemento é frequentemente utilizado nas atividades agrícolas, estando presentes em diversos produtos, incluindo agrotóxicos (BENITES et al., 2014). Dentre os metais avaliados neste trabalho, o zinco é o que possui menor toxicidade, além de não ser mutagênico em si, e ser considerado um elemento necessário na proliferação celular. A falta desse elemento em plantas, por exemplo, leva à repressão de seu crescimento (FLOREA et al., 2006).

\section{Análises citogenéticas em Allium cepa L.}

\section{Avaliação da citotoxicidade}

Os valores de Índice Mitótico (IM) observados nos experimentos possibilita inferir o potencial citotóxico dos diferentes pontos de coleta de água do córrego do Limoeiro, usando o controle negativo como comparação. Smaka-Kincl et al. (1996) mostrou que a diminuição do IM em células meristemáticas de Allium cepa pode ser considerado um método confiável para determinar a presença de agentes citotóxicos no ambiente e, portanto, pode ser considerado como um teste sensível para estimar os níveis de poluição.

Ao avaliar as células meristemáticas de Allium cepa em processo de divisão celular, foi possível determinar o IM para cada grupo de amostras hídricas coletadas. Os valores encontrados estão descritos nas Tabela 5 (período chuvoso) e na Tabela 6 (período seco). Na primeira fase do experimento (período chuvoso) foi realizada avaliação do controle positivo $\left(\mathrm{H}_{2} \mathrm{O}_{2}\right.$ a $\left.0,3 \mathrm{M}\right)$ como forma de avaliar a sensibilidade do teste, juntamente com a avaliação do controle negativo e dos pontos de coleta selecionados.

Através da análise variância ANOVA e do teste de Dunnett foi verificado que o procedimento experimental foi eficaz, com valores significativos ao nível de 1\%. Estatisticamente, os pontos P2 e P4 tiveram redução significativa do IM se comparados ao controle negativo, revelando que estes pontos apresentam contaminação por substâncias citotóxicas (Tabela 5).

No período seco, os pontos que sofreram variação significativa foram P2, P3 e P5 se comparados ao controle negativo, tal como apresentado na Tabela 6. Nos gráficos das Figuras 2 e 3, pode-se observar também a diferença estatística entre todos os grupos através de agrupamento pelo teste de Tukey. Sabe-se que as análises do IM possibilitam a avaliação da citotoxicidade de diversas substâncias presentes em amostras de água poluída ou contaminada (CUCHIARA et al., 2012). Conforme exposto pelos autores, tanto 
o aumento quanto a diminuição do IM são importantes indicadores no monitoramento da poluição ambiental.

Tabela 5: Índice mitótico dos meristemas radiculares de A. cepa referentes ao mês de fevereiro de 2018 (período chuvoso).

\begin{tabular}{|c|c|c|c|c|c|c|}
\hline \multirow[t]{2}{*}{ Grupos } & \multirow[t]{2}{*}{ Índice Mitótico IM (\%) } & \multicolumn{5}{|c|}{ Número de células nas diferentes fases } \\
\hline & & Interfase & Prófase & Metáfase & Anáfase & Telófase \\
\hline Controle Negativo & 6.89 & 6435 & 181 & 93 & 77 & 125 \\
\hline Controle Positivo & $2.95^{* *}$ & 6354 & 88 & 58 & 19 & 28 \\
\hline P1 & 5.14 & 5742 & 127 & 24 & 61 & 99 \\
\hline $\mathrm{P} 2$ & $4.56^{*}$ & 6259 & 90 & 45 & 55 & 109 \\
\hline P3 & 5.73 & 6521 & 148 & 69 & 44 & 135 \\
\hline P4 & $4.67 * *$ & 6041 & 130 & 45 & 32 & 89 \\
\hline P5 & 5.36 & 6019 & 115 & 49 & 48 & 129 \\
\hline
\end{tabular}

Fonte: Malaman (2019).

* Significativo ao nível de $5 \%(p \leq 0.05),{ }^{* *}$ Significativo ao nível de $1 \%(p \leq 0.01)$ se comparados ao controle negativo.

Tabela 6: Índice mitótico dos meristemas radiculares das cebolas referentes ao mês de Setembro de 2018 (período seco).

\begin{tabular}{|l|l|l|l|l|l|l|}
\hline \multirow{2}{*}{ Grupos } & \multirow{2}{*}{ Índice Mitótico IM (\%) } & \multicolumn{4}{l}{ Número de células nas diferentes fases } \\
\cline { 3 - 7 } & & Interfase & Prófase & Metáfase & Anáfase & Telófase \\
\hline Controle Negativo & 8.78 & 6141 & 267 & 89 & 113 & 122 \\
\hline Ponto 1 & 9.75 & 6038 & 284 & 134 & 107 & 127 \\
\hline Ponto 2 & $6.72^{* *}$ & 6403 & 201 & 81 & 72 & 106 \\
\hline Ponto 3 & $6.15^{* *}$ & 5810 & 158 & 65 & 46 & 112 \\
\hline Ponto 4 & 8.27 & 6143 & 248 & 82 & 83 & 141 \\
\hline Ponto 5 & $7.11^{* *}$ & 5957 & 216 & 70 & 73 & 97 \\
\hline
\end{tabular}

Fonte: Malaman (2019).

* Significativo ao nível de $5 \%$ ( $p \leq 0.05)$, ** Significativo ao nível de $1 \%(p \leq 0.01)$ se comparados ao controle negativo.

Os valores de IM observados em todos os grupos avaliados no período chuvoso foram inferiores aos valores de IM do controle negativo, mas somente em P2 e P4 essa redução foi significativa. Nos grupos avaliados durante o período seco, os valores de IM de P1 foi o único superior ao controle negativo. Os demais pontos apresentaram valores de IM inferiores ao controle, mas somente em P2, P3 e P5 essa variação foi significativa. Esses dados podem ser melhor observados nos gráficos representados nas Figuras 2 e 3 .

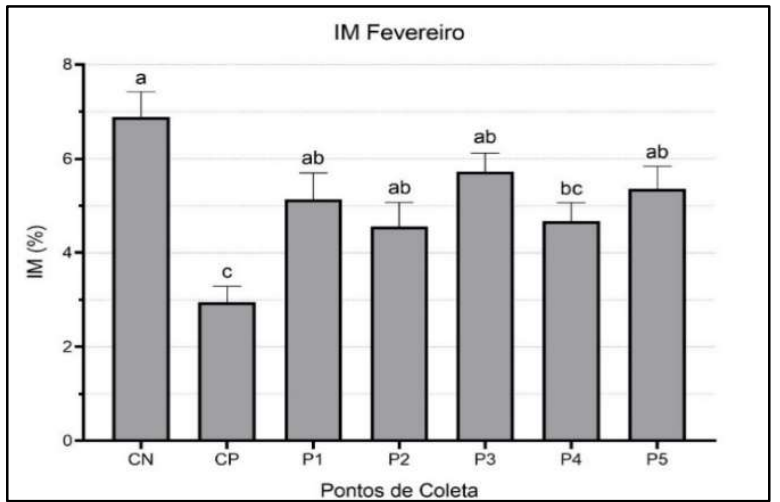

Figura 2: Índice mitótico dos grupos no período chuvoso.

Médias que não compartilham uma letra são significativamente diferentes (Teste Tukey; $p<0,05$ )

Fonte: Malaman (2019).

A diminuição do IM dos grupos tratados em relação ao controle negativo, pode ser indício da presença de substâncias que provocam ações químicas no crescimento e no desenvolvimento do organismo exposto. Porém, é importante ressaltar que, além dos metais pesados, outras substâncias já testadas são 
capazes de inibir a divisão celular no estágio anterior à mitose (LERDA, 1992).

\section{Avaliação da genotoxicidade}

A avaliação da genotoxicidade do Córrego do Limoeiro foi realizada através da comparação dos índices de Anomalias Cromossômicas (AC). Para tanto, foi utilizado como parâmetro de determinação da ocorrência de células normais e anormais as imagens representadas na Figura 4, que demonstram células em processo de divisão mitótica sem a ocorrência de anomalias.

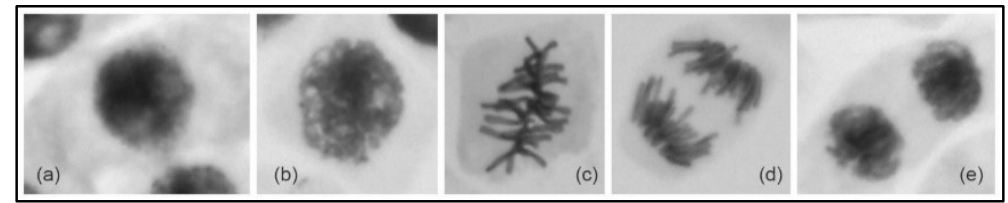

Figura 4: Fases da mitose sem ocorrência de anomalias em Allium cepa L.: Interfase (a); Prófase (b); Metáfase (c); Anáfase (d); Telófase (e). Fonte: Malaman (2019).

Entre as anomalias cromossômicas mais frequentes, foram observadas a ocorrência de: pontes cromossômicas durante a anáfase e a telófase, o atraso na separação de cromátides irmãs durante a anáfase, cromossomos pegajosos, fragmentos cromossômicos, C-mitoses e poliploidia. Alguns exemplos destas observações são apresentados na Figura 5.

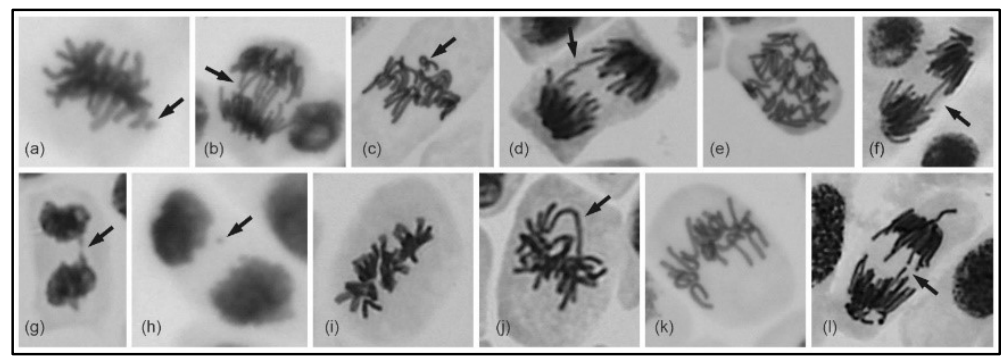

Figura 5: Principais tipos de anomalias cromossômicas identificadas: metáfase com fragmento cromossômico (a); anáfase com pontes cromossômicas (b); metáfase com perda cromossômica (c); anáfase com cromossomos pegajosos e atraso na separação de cromátides (d); metáfase poliploide (e); anáfase com ponte cromossômica (f); telófase com

atraso na separação de cromátide (g); telófase com quebra cromossômica (h); c-mitose (i, k); metáfase com cromossomos soltos (j); anáfase com cromossomos atrasados e pegajosos (I). Fonte: Malaman (2019).

Após a contagem total das células em divisão, foram calculados os índices de Anomalias Cromossômicas (AC) para cada um dos grupos experimentais avaliados. Os resultados observados estão apresentados nas Tabela 7 e 8, respectivamente para as coletas realizadas nos períodos chuvoso e seco.

Tabela 7: Índice de Anomalias Cromossômicas referentes ao período chuvoso.

\begin{tabular}{|l|l|l|l|l|l|l|l|l|l|l|l|}
\hline Grupos & P & AC & M & AC & A & AC & T & AC & Total Mitoses & Total AC & Frequência AC (\%) \\
\hline CN & 125 & 0 & 109 & 4 & 87 & 6 & 92 & 1 & 413 & 11 & $2,66 \%$ \\
\hline CP & 28 & 1 & 33 & 3 & 19 & 3 & 15 & 4 & 95 & 11 & $11,58 \% * *$ \\
\hline P1 & 88 & 1 & 28 & 1 & 43 & 5 & 38 & 0 & 197 & 7 & $3,55 \%$ \\
\hline P2 & 65 & 2 & 44 & 3 & 41 & 5 & 34 & 1 & 184 & 11 & $5,98 \%$ \\
\hline P3 & 101 & 1 & 76 & 7 & 49 & 4 & 45 & 0 & 271 & 12 & $4,43 \%$ \\
\hline P4 & 67 & 0 & 58 & 1 & 41 & 6 & 41 & 3 & 207 & 10 & $4,83 \%$ \\
\hline P5 & 66 & 0 & 79 & 7 & 54 & 12 & 49 & 1 & 248 & 20 & $8,06 \% * *$ \\
\hline
\end{tabular}

Fonte: Malaman (2019).

$\mathrm{P}=$ prófase; $\mathrm{M}=$ metáfase; $\mathrm{A}=$ anáfase; $\mathrm{T}$ = telófase; $\mathrm{AC}=$ anomalias cromossômicas.

* Significativo ao nível de 5\% ( $p \leq 0.05)$, ** Significativo ao nível de $1 \%(p \leq 0.01)$ se comparados ao controle 
Tabela 8: Índice de Anomalias Cromossômicas referentes ao período seco.

\begin{tabular}{|l|l|l|l|l|l|l|l|l|l|l|l|}
\hline Grupos & P & AC & M & AC & A & AC & T & AC & Total Mitoses & Total AC & Frequência AC (\%) \\
\hline CN & 259 & $\mathbf{0}$ & 122 & 1 & 174 & 10 & 110 & 2 & 665 & 13 & 1,95 \\
\hline P1 & 186 & 0 & 124 & 6 & 140 & 9 & 120 & 0 & 570 & 15 & 2,63 \\
\hline P2 & 129 & 0 & 81 & 2 & 96 & 10 & 79 & 2 & 385 & 14 & $3,63^{*}$ \\
\hline P3 & 122 & 0 & 76 & 5 & 93 & 5 & 70 & 2 & 361 & 12 & 3,32 \\
\hline P4 & 66 & 0 & 105 & 3 & 137 & 15 & 135 & 2 & 443 & 20 & $4,51^{* *}$ \\
\hline P5 & 94 & 0 & 97 & 6 & 116 & 6 & 89 & 0 & 396 & 12 & 3,03 \\
\hline
\end{tabular}

Fonte: Malaman (2019).

$\mathrm{P}=$ prófase; $\mathrm{M}=$ metáfase; $\mathrm{A}=$ anáfase; $\mathrm{T}$ = telófase; $\mathrm{AC}=$ anomalias cromossômicas.

* Significativo ao nível de 5\% ( $p \leq 0.05)$, ** Significativo ao nível de $1 \%(p \leq 0.01)$ se comparados ao controle

Pode-se notar que, no período chuvoso, somente P5 apresentou um potencial genotóxico significativo em comparação ao controle negativo, enquanto que, no período seco, foi constatado um potencial genotóxico significativo na amostra coletada em P4, em comparação ao controle negativo naquela estação climática.

Esses resultados podem ser melhor analisados através dos gráficos representados nas Figuras 6 e 7, respectivamente para os grupos experimentais avaliados nos períodos chuvoso e seco. Nesta forma de apresentação, pode-se notar as diferenças estatísticas entre os diferentes grupos experimentais e que foram detectadas pelo teste de Tukey, bem como a sua comparação em relação aos respectivos controles negativo e positivo para cada estação.

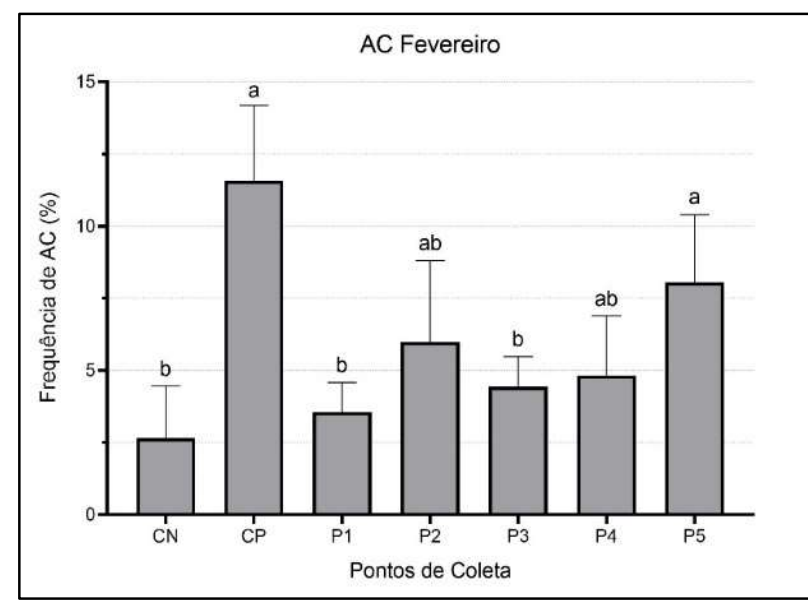

Figura 6: Frequência de anomalias cromossômicas (AC) das amostras coletadas no período chuvoso.

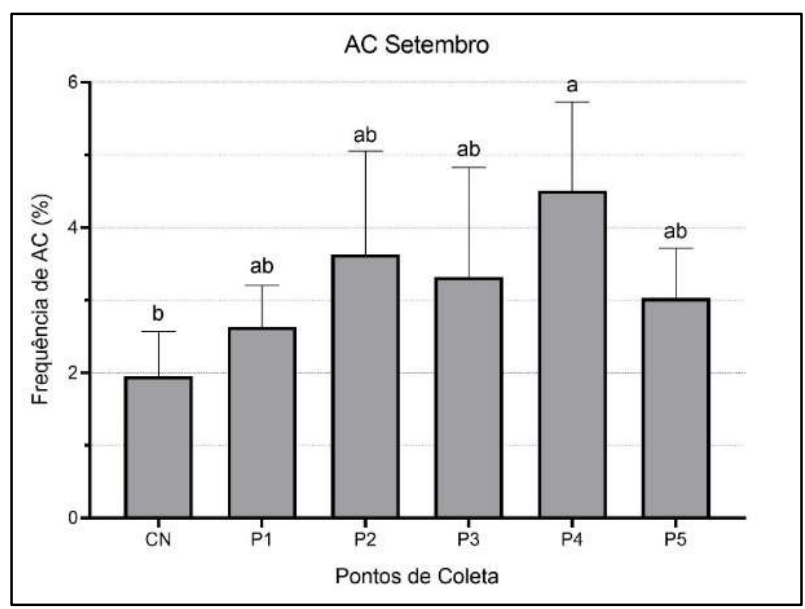

Figura 7: Frequência de anomalias cromossômicas (AC) das amostras coletadas no período seco.

Médias que não compartilham uma letra são significativamente diferentes (Teste Tukey; $p<0,05$ )

Fonte: Malaman (2019).

De acordo com inúmeros autores, entre eles os estudos desenvolvidos por Natarajan (2002) e Pereira et al. (2014), alterações cromossômicas são reconhecidas como consequência das ações genotóxicas de agentes químicos. As diferenças de genotoxicidade entre os vários pontos de coleta em um rio podem estar relacionadas ao volume de água (variação na concentração dos agentes genotóxicos) e/ou ao efeito cumulativo de diferentes fontes (MATSUMOTO et al., 2006). Por este motivo foram escolhidos cinco (5) pontos amostrais nesta pesquisa, considerando lugares com diferentes características de atividades antrópicas e que, desta forma, possibilite relacionar os resultados observados às respectivas atividades.

A sazonalidade também foi avaliada devido ao efeito de diluição que ocorre nos períodos de chuva. Os resultados encontrados por Scalon et al. (2010), mostraram que a genotoxicidade do Rio dos Sinos, 
avaliada através do teste Allium cepa foi mais significativo durante a primavera e o verão, e menos significativo no outono e inverno, sugerindo influência das diferenças sazonais de precipitação pluviométrica.

$\mathrm{Na}$ presente pesquisa, essa variação não foi constatada de forma clara, pois os pontos que apresentaram valores de AC significativos foram diferentes para os dois períodos, embora em ambas estações estejam predominantes nos pontos localizados mais distantes da região urbana, respectivamente P4 e P5 para os períodos seco e chuvoso. Ressalta-se que o impacto genotóxico das águas residuais sobre o meio ambiente e para a saúde humana são difíceis de prever, devido às misturas complexas de substâncias químicas, e uma interpretação completa de seu efeito requer mais que análises químicas (ODEIGAH et al.,1997).

\section{CONCLUSÕES}

Esta pesquisa demonstra a necessidade da realização bioensaios no biomonitoramento ambiental juntamente com as outras análises de qualidade de água. Desta forma é possível determinar a saúde ambiental de locais com importância social e econômica. Em muitos casos não é viável avaliar o impacto ambiental de um corpo d'água apenas através das avaliações físico-químicos. A interação entre substâncias já conhecidas no local e a presença de substâncias que ainda não foram avaliadas pode refletir a necessidade de ações de conservação ambiental que não são detectáveis por estes métodos. Por isso é de extrema importância a realização de testes de citogenotoxicidade e mutagenicidade juntamente aos demais testes.

O teste Allium cepa, confirmou neste trabalho, ser bastante sensível aos diferentes tipos de poluição. Ficou demostrado que diferentes atividades antrópicas podem interferir de forma diferente na qualidade de um mesmo curso d'água. Isso ficou evidente através dos dados apurados na região da ETE. Através das correlações estabelecidas supõe-se que a presença de matéria orgânica, juntamente ao zinco e o cromo, foram as substâncias que, possivelmente, atuaram de forma danosa às células e ao material genético. Entretanto deve-se levar em consideração que a presença de outras substâncias não avaliadas neste estudo podem, também, estar relacionadas aos dados obtidos, de forma direta ou sinergicamente.

Mesmo sendo aceito como um ótimo mecanismo de biomonitoramento ambiental, o teste Allium cepa apresenta restrições nas avaliações de algumas classes de substâncias (UHL et al., 2003) devido às grandes diferenças metabólicas entre os organismos vegetais e animais. Entretanto, os resultados obtidos através da presente pesquisa podem ser extrapolados para muitos outros organismos que são expostos diariamente ao contato com as águas contaminadas do córrego do Limoeiro, mas servem principalmente como sinal de alerta para os riscos provenientes da exposição contínua de outros organismos, incluindo seres humanos, aos seus efeitos citotóxicos.

Impactos ambientais em pequenos corpos d'água, como o Córrego do Limoeiro, são muitas vezes subestimados por sua discreta importância perante os grandes rios de abastecimento urbano e aos grandes impactos ambientais. Entretanto, os dados obtidos por esse estudo reforçam a necessidade de conservação dos pequenos afluentes, pois estes são objetos importantes na identificação de impactos ambientais causados pela ação humana e servem de alerta para que se faça um monitoramento mais criterioso em 
relação às substâncias que são lançadas no meio ambiente.

AGRADECIMENTOS: pelo apoio da Coordenação de Aperfeiçoamento de Pessoal de Nível Superior - Brasil (CAPES) - Código de Financiamento 001.

\section{REFERÊNCIAS}

AMORIM, M. C. C. T.; DUBREUIL, V.; QUENO, H.; SANT'ANANETO, J. L.. Características das ilhas de calor em cidades de porte médio: exemplos de Presidente Prudente (Brasil) e Rennes (França). Revista Franco-Brasileira de Geografia, Confins, n.7, 2009. DOI: http://doi.org/10.4000/confins.6070

ANACLETO, L. R.; ROBERTO, M. M.; MARIN-MORALES, M. A.. Toxicological effects of the waste of the sugarcane industry, used as agricultural fertilizer, on the test system Allium cepa. Chemosphere, v.173, p.31-42, 2017. DOI:

http://doi.org/10.1016/j.chemosphere.2017.01.033

APHA. Standard methods for the examination of water and wastewater. Washington: American Public Health Association, 2012.

BARBÉRIO, A.; VOLTOLINI, J. C.; MELLO, M. L. S.. Standardization of bulb and root sample sizes for the Allium cepa test. Ecotoxicology, v.20, n.4, p.927-935, 2011. DOI: http://doi.org/10.1007/s10646-011-0602-8

BENITES, L. M.; DONCATO, K.; PERAZZO, G.; MINHO, T. S. . Avaliação do potencial mutagênico de cobre da água do rio Uruguai. Ciência e Natura, v.36, n.2, p.107-113, 2014. DOI: http://doi.org/10.5902/2179460X13610

BOAVENTURA, D. T. C.; OLIVEIRA, A. G. C.; GARCIA, R. M.. Diagnóstico ambiental nas áreas de cabeceiras de drenagem da Bacia Hidrográfica do Balneário da Amizade-Álvares Machado e Presidente Prudente/SP. In: ENCONTRO NACIONAL DOS GEÓGRAFOS, 16. Anais. Porto Alegre: AGB, 2010.

BOLLANI, S.; CABO, L.; CHAGAS, C.; MORETTON, J.. Genotoxicity of water samples from an area of the Pampean region (Argentina) impacted by agricultural and livestock activities. Environmental Science and Pollution Research, v.26, n.9, p.1-9, 2018. Dol: http://doi.org/10.1007/s11356018-3263-9

BONCIU, E.; FIRBAS, P.; FONTANETTI, C. S.; WUSHENG, J.; KARAISMAILOGLU, M. C.; LIU, D.; MENICUCCI, F.; PESNYA, D. S.; POPESCU, A.; ROMANOVSKY, A. V.; SCHIFF, S.; SLUSARCZYK, J.; SOUZA, C. P.; SRIVASTAVA, A.; SUTAN, A.; PAPINI, A.. An evaluation for the standardization of the Allium cepa test as cytotoxicity and genotoxicity assay. Caryologia, v.71, n.3, p.191-209, 2018. Dol: http://doi.org/10.1080/00087114.2018.1503496

BRASIL. Resolução CONAMA 357, de 17 de março de 2005. Conselho Nacional de Meio Ambiente. Brasília, 2005.

CAMPAROTO, M. L.; TEIXEIRA, R. O.; MANTOVANI, M. S.; VICENTINI, V. E. P.. Effects of Maytenus ilicifolia Mart. and Bauhinia candicans Benth infusions on onion root-tip and rat bone-marrow cells. Genetics and Molecular Biology, v.25, n.1, p.85-89, 2002. DOI: http://doi.org/10.1590/S1415-

\section{6}

CETESB. Companhia de Tecnologia Ambiental do Estado de São Paulo. Guia nacional de coleta e preservação de amostras: água, sedimento, comunidades aquáticas e efluentes líquidas. São Paulo: CETESB; Brasília; ANA, 2011.

CHANDEL, S.; KAUR, S.; ISSA, M.; SINGH, H. P.; BATISH, D. R. $\mathrm{KOHLI}, \mathrm{R}$. K.. Exposure to mobile phone radiations at 2350 $\mathrm{MHz}$ incites cyto- and genotoxic effects in root meristems of Allium cepa. Journal of Environmental Health Science and Engineering, v.17, n.1, p.97-104, 2019. DOI: http://doi.org/10.1007/s40201-018-00330-1

CUCHIARA, C. C.; BORGES, C. D. S.; BOBROWSKI, V. L.. Sistema teste de Allium cepa como bioindicador da citogenotoxicidade de cursos d'água. Tecnologia \& Ciências Agropecuárias, João Pessoa, v.6, n.1, p.33-38, 2012.

EVSEEVA, T. I.; GERASKIN, S. A.; SHUKTOMOVA, I. I.. Genotoxicity and toxicity assay of water sampled from a radium production industry storage cell territory by means of Allium-test. Journal of Environmental Radioactivity, v.68, n.3, p.235-248, 2003. DOI: http://doi.org/10.1016/S0265931X(03)00054-7

FILIPIČ, M.. Mechanisms of cadmium induced genomic instability. Mutation Research/Fundamental and Molecular Mechanisms of Mutagenesis, v.733, n.1-2, p.69-77, 2012. DOI: http://doi.org/10.1016/j.mrfmmm.2011.09.002

FISKESJÖ, G.. The Allium test as a standard in environmental monitoring. Hereditas, v.102, n.1, p.99-112, 1985. DOI: http://doi.org/10.1111/j.1601-5223.1985.tb00471.x

FLOREA, A. M.; BÜSSELBERG, D.. Occurrence, use and potential toxic effects of metals and metal compounds. Biometals, v.19, n.4, p.419-427, 2006. DOI: http://doi.org/10.1007/s10534-005-4451-x

GERBER, G. B.; LÉONARD, A.; JACQUET, P.. Toxicity, mutagenicity and teratogenicity of lead. Mutation Research/Reviews in Genetic Toxicology, v.76, n.2, p.115141, 1980. DOI: http://doi.org/10.1016/01651110(80)90006-8

GONZÁLEZ-FERNÁNDEZ, A.; LÓPEZ-SÁEZ, J. F.; GIMÉNEZMARTÍN, G. Duration of the division cycle in binucleate and mononucleate cells. Experimental Cell Research, v.43, n.2, p.255-267, 1966. DOI: http://doi.org/10.1016/00144827(66)90053-X

GRANT, W. F.. Chromosome aberration assays in Allium - A report of the U.S. Environmental Protection Agency GeneTox Program. Mutation Research, v.99, n.1, p.273-291, 1982. DOI: http://doi.org/10.1016/0165-1110(82)90046-X 
GRANT, W. F.. The present status of higher plant bioassays for the detection of environmental mutagens. Mutation Research/Fundamental and Molecular Mechanisms of Mutagenesis, v.310, n.2, p.175-185, 1994. DOI: http://doi.org/10.1016/0027-5107(94)90112-0

GUERRA, M.; SOUZA, M. J.. Como Observar Cromossomos: Um Guia de Técnicas em Citogenética Vegetal, Animal e Humana. Ribeirão Preto: Fundação de Pesquisas Científicas de Ribeirão Preto, 2002.

HARA, R. V.; MARIN-MORALES, M. A.. In vitro and in vivo investigation of the genotoxic potential of waters from rivers under the influence of a petroleum refinery (São Paulo State - Brazil). Chemosphere, v.174, p.321-330, 2017. DOI: http://doi.org/10.1016/j.chemosphere.2017.01.142

HONDA, S. C. A. L.; VIEIRA, M. C.; ALBANO, M. P.; MARIA, Y. R.. Planejamento ambiental e ocupação do solo urbano em Presidente Prudente (SP). Urbe. Revista Brasileira de Gestão Urbana, v.7, n.1, p.62-73, 2015. DOI: http://doi.org/10.1590/2175-3369.007.001.AO04

IBGE. Instituto Brasileiro de Geografia e Estatística. Cidades. Rio de Janeiro: IBGE, 2017.

LERDA, D.. The effect of lead on Allium cepa L. Mutation Research Letters, v.281, n.2, p.89-92, 1992. DOI: http://doi.org/10.1016/0165-7992(92)90041-F

MALAMAN, A. C. P.. Avaliação da citogenotoxicidade de águas fluviais na área urbana do município de Presidente Prudente - SP, através do teste Allium cepa L. Dissertação (Mestrado em Meio Ambiente e Desenvolvimento Regional) - Universidade do Oeste Paulista, Presidente Prudente, 2019.

MATSUMOTO, S. T.; MANTOVANI, M. S.; MALAGUTTII, M. I. A.; DIAS, A. L.; FONCECA, I. C.; MARIN-MORALES, M. A.. Genotoxicity and mutagenicity of water contaminated with tannery effluents, as evaluated by the micronucleus test and comet assay using the fish Oreochromis niloticus and chromosome aberrations in onion root-tips. Genetics and Molecular Biology, v.29, n.1, p.148-158, 2006. DOI: http://doi.org/10.1590/S1415-47572006000100028

MATSUMOTO, S. T.; MARIN-MORALES, M. A.. Mutagenic Potential Evaluation of the Water of a River That Receives Tannery Effluent Using the Allium cepa Test System. Cytologia, v.69, n.4, p.399-408, 2004. DOI: http://doi.org/10.1508/cytologia.69.399

MELLO, M. L. S.; VIDAL, B. C.. The Feulgen reaction: A brief review and new perspectives, Acta Histochemica, v.119, n.6, p.603-609, 2017. DOI:

http://doi.org/10.1016/j.acthis.2017.07.002

NATARAJAN, A. T.. Chromosome aberrations: past, present and future. Mutation Research/Fundamental and Molecular Mechanisms of Mutagenesis, v.504, n.1-2, p.316, 2002. DOI: http://doi.org/10.1016/S00275107(02)00075-1

ODEIGAH, P. G.; SAMUEL, A.; AMUND, O.; LLORI, M. O.. Genotoxicity Screening of Leachates from Solid Industrial Wastes Evaluated with the Allium Test. ATLA Alternatives to Laboratory Animals, Abuja, 1997, v.25 p.311-321.
OGUNYEMI, A.; SAMUEL, A.; AMUND, O.; LLORI, M. O.. Toxicity evaluation of waste effluent from cassavaprocessing factory in Lagos state, Nigeria using the Allium cepa assay. Ife Journal of Science, v.20, n.2, p.305-315, 2018. DOI: http://doi.org/10.4314/ijs.v20i2.11

PRÁ, D.; FRANKE, S. I. R.; GIULIAN, R.; YONEAMA, M. L.. Genotoxicity and mutagenicity of iron and copper in mice. BioMetals, v.21, n.3, p.289-297, 2008. DOI: http://doi.org/10.1007/s10534-007-9118-3

PEREIRA, R. D.; FLUMINHAN, A.. Bioensaios envolvendo Tradescantia pallida cv purpurea relacionados à reciclagem agrícola de biossólidos. In: Água: Tratamento, Efluentes e Lodos, Tupã, SP. 2 ed. ANAP, 2017. p.143-164.

PEREIRA, R. D.; YAGUINUMA, D. H.; FLUMINHAN, A.. Efeitos clastogênicos em Tradescantia pallida cv purpurea cultivada em solos tratados com lodos de diferentes origens. Fórum Ambiental da Alta Paulista, v.10, n.12, p.234-254, 2014.

RANK, J.; NIELSEN, M. H.. Evaluation of the Allium anaphasetelophase test in relation to genotoxicity screening of industrial wastewater. Mutation Research/Environmental Mutagenesis and Related Subjects, v.312, n.1, p.17-24, 1994. DOI: http://doi.org/10.1016/0165-1161(94)90004-3

RICHARDSON, S. D.; PLEWA, M. J.; WAGNER, E. D.; SCHOENY, R.; MARINI, D. M.. Occurrence, genotoxicity, and carcinogenicity of regulated and emerging disinfection byproducts in drinking water: a review and rodmap for research. Mutation Research/Reviews in Mutation Research, v.636, n.1-3, p.178-242, 2007. DOI: http://doi.org/10.1016/j.mrrev.2007.09.001

SCALON, M. C. S.; RECHENMACHER, C.; SIEBEL, A. M.; KAYSER, M. L.; RODRIGUES, M. T.; MALUF, S. W.; RODRIGUES, M. A. S.; SILVA, L. B.. Evaluation of Sinos River water genotoxicity using the comet assay in fish. Brazilian Journal of Biology, v.70, n.4, p.1217-1222, 2010.

SMAKA-KINCL, V.; STEGNAR, P.; LOVKA, M.; TOMAN, M. J.. The evaluation of waste, surface and ground water quality using the Allium test procedure. Mutation Research/Genetic Toxicology, Amsterdam, v.368, n.3-4, p.171-179, 1996. DOI: http://doi.org/10.1016/S0165-1218(96)90059-2

SOARES, F. B.; LEAL, A. C.. Planejamento ambiental da bacia do Balneário da Amizade nos municípios de Álvares Machado e Presidente Prudente - São Paulo. Periódico Eletrônico Fórum Ambiental da Alta Paulista, v.7, n.2, 2011. DOI: http://doi.org/10.17271/19800827722011105

SOMAR METEREOLOGIA. Dados registrados no mês de Agosto de 2019 em Presidente Prudente/SP. Presidente Prudente: SOMAR METEREOLOGIA, 2019.

TAKENAKA, E.; SILVA, B. A. P.; ROCHA, S. R. D.. Águas residuais industriais: o caso de um frigorífico no município de Presidente Prudente - SP. Periódico Eletrônico Fórum Ambiental da Alta Paulista, v.9, n.11, p.167-176, 2013. DOI: http://doi.org/10.17271/198008279112013669

TEODORO, P. H. M.; NUNES, J. O. R.. Os alagamentos em Presidente Prudente/SP: um trabalho interdisciplinar embasado no mapeamento geomorfológico. Revista Formação, v.2, n.17, p.81-102, 2011. DOI: 
https://doi.org/10.33081/formacao.v2i17.456

UHL, M.; PLEWA, M. J.; MAJER, B. J.; KNASMÜLLER, S.. Basic principles of genetic toxicology with an emphasis on plant bioassays. In: MALUSZYNSKA, J.; PLEWA, M.. Bioassays in Plant Cells for Improvement of Ecosystem and human Health: A course manual. Katowice, 2013. p.11-30.

VANZELLA, T. P.; MARTINEZ, C. B. R.; CÓLUS, I. M. S.. Genotoxic and mutagenic effects of diesel oil water soluble fraction on a neotropical fish species. Mutation Research/Genetic Toxicology and Environmental Mutagenesis, v.631, n.1, p.36-43, 2007. DOI:

http://doi.org/10.1016/j.mrgentox.2007.04.004
VICENTINI, V. E. P.; CAMPAROTO, M.; TEIXEIRA, R. O.; MANTOVANI, M. S.. Averrhoa carambola L., Syzygium cumini (L.) Skeels and Cissus sicyoides L.: medicinal herbal tea effects on vegetal and animal test systems. Acta Scientiarum Biological Sciences, v.23, n.2, p.593-598, 2001.

VILLANUEVA, C. M.; CANTOR, K. P.; GRIMALT, J. O.; MALATS, N.; SILVERMAN, D.; TARDON, A.; GARCIA-CLOSAS, R.; SERRA, C.; CARRATO, A.; CASTAÑO-VINYALS, G.; MARCOS, R.; ROTHMAN, N.; REAL, F. X.; DOSEMECI, M.; KOGEVINAS, M. Bladder cancer and exposure to water disinfection byproducts trough ingestion, bathing, showering and swimming in pools. American Journal of Epidemiology, v.165, p.148-156, 2007. DOI:

http://doi.org/10.1093/aje/kwj364

A CBPC - Companhia Brasileira de Produção Científica (CNPJ: 11.221.422/0001-03) detém os direitos materiais desta publicação. Os direitos referem-se à publicação do trabalho em qualquer parte do mundo, incluindo os direitos às renovações, expansões e disseminações da contribuição, bem como outros direitos subsidiários. Todos os trabalhos publicados eletronicamente poderão posteriormente ser publicados em coletâneas impressas sob coordenação da Sustenere Publishing, da Companhia Brasileira de Produção Científica e seus parceiros autorizados. Os (as) autores (as) preservam os direitos autorais, mas não têm permissão para a publicação da contribuição em outro meio, impresso ou digital, em português ou em tradução. 